\title{
Aspects of Acidosis in Ruminants with a Focus on Nutrition: A Review
}

\author{
Tiago Neves Pereira Valente ${ }^{1}$, Cláudia Batista Sampaio ${ }^{2}$, Erico da Silva Lima ${ }^{3}$, Bruno Borges Deminicis ${ }^{4}$, \\ Andréia Santos Cezário ${ }^{5} \&$ Wallacy Barbacena Rosa dos Santos ${ }^{5}$ \\ ${ }^{1}$ Instituto Federal Goiano, Posse, GO, Brazil \\ ${ }^{2}$ University Federal of Viçosa, Viçosa, MG, Brazil \\ ${ }^{3}$ United Metropolitan Universities, São Paulo, SP, Brazil \\ ${ }^{4}$ University of Southern Bahia, Teixeira de Freitas, BA, Brazil \\ ${ }^{5}$ Instituto Federal Goiano, Morrinhos, GO, Brazil \\ Correspondence: Tiago Neves Pereira Valente, Instituto Federal Goiano, Campus Posse, GO, Rua Correntina, ${ }^{\circ}$ \\ 824, Setor Dom Prudêncio, CEP 73900-000, Brazil. Tel: 55-64-981-097-444. E-mail: \\ tiago.valente@ifgoiano.edu.br
}

Received: January 2, $2017 \quad$ Accepted: January 22, $2017 \quad$ Online Published: February 15, 2017

doi:10.5539/jas.v9n3p90 URL: http://dx.doi.org/10.5539/jas.v9n3p90

The research is financed by Instituto Federal Goiano, Brazil.

\begin{abstract}
An increased risk of acidosis in animals is associated with a high dry matter intake (DMI), which in turn results in the consumption of more fermentable organic matter $(\mathrm{OM})$ in the rumen leading to a high production of volatile fatty acids (VFA). This is observed in lactating dairy cows and animals in a feedlot. Acute acidosis occurs when there is a severe drop in the $\mathrm{pH}$ of the rumen. A prolonged period when $\mathrm{pH}$ of in rumen remains low, it leads to sub-acute ruminal acidosis (SARA), which is a temporary imbalance between acid production and absorption. An associated change of an acute increase in the ruminal osmolarity and the accumulation of glucose and lactate in its stereoisomeric forms (D-lactate and L-lactate), is observed in the rumen fluid. However, in the sub-acute form, the accumulation of lactic acid occurs in the rumen. To a great extent, these changes in the rumen are due to high concentrations of VFA. The best way to avoid problems with ruminal acidosis is an adequate supply of neutral detergent fiber (NDF) in the diet, preferentially with large particle size and length to stimulate rumination and consequently greater buffering efficiency, thus maintaining the balance between $\mathrm{pH}$ and microorganisms in the rumen.
\end{abstract}

Keywords: D-lactate, metabolic disorder, sub-acute ruminal acidosis

\section{Introduction}

Acidosis is defined as a state of high pathological acidity of the blood, increasing in ruminants and may include situations of acidity ruminal or systemic, representing the most important nutritional disorder in dairy cattle and beef cattle in feedlot. Caused by a rapid production and absorption of acids in the rumen when excessive starch consumption (grains) or sugar in a short period of time (Russell, 2002; Pan et al., 2016). This disease is relatively a common form of metabolic acidosis, characterized by a blood lactate level greater than $5 \mathrm{mmol} / \mathrm{L}$ (normal: 1.2 $\mathrm{mmol} / \mathrm{L}$ ) (Plaizier et al., 2009). Acidosis takes the animal to a stress condition that can lead from anorexia to reducing the production potential of the animal reaching pathological conditions such as milk fat depression, low feed intake, laminitis and could result in the death of the animal (Hernandéz et al., 2014). However, the opinion that a reduced ruminal $\mathrm{pH}$ is the sole reason for digestive and metabolic disorders in dairy cattle is likely an oversimplification of the complexity of the ruminal ecosystem. The include more long fibrous material in the diet maintaining rumen health. Despite, an increase in the consumption of concentrates and sometimes the use of highly-fermentable forages can lead to alterations in the normal rumen fermentation leading to digestive disturbances (Owens \& Basalan, 2016).

Acute acidosis occurs when rumen $\mathrm{pH}$ drops severely and remains low for an extended period of time and sub-acute ruminal acidosis (SARA) is a temporary imbalance between acid production and absorption. Second Van Vuuren et al. (2012) propose to re-name SARA the "high-concentrate syndrome". The term SARA suggests 
that increasing ruminal $\mathrm{pH}$ per se will prevent or reduce the negative consequences. However, dietary supplements that neutralize or buffer ruminal $\mathrm{pH}$ can not always result in a complete recovery of the animal. On the other hand, SARA fermentation profiles can develop when high concentrate diets are supplied even when $\mathrm{pH}$ is above the SARA threshold. Therefore, they suggest a combination of $\mathrm{pH}$ modulating strategies and microbial population control to reduce the consequences of this syndrome. Healthy functioning of the reticulo-rumen is a crucial pre-requisite for performance and health of cattle. Rumen fermentation accounts for 0.8 of total fibre digestion in cattle (Archimède et al., 1997).

Ruminal acidosis is caused by an imbalance between the production of acids in the rumen from the ruminal fermentation of carbohydrates and the removal of these organic acids for the absorption by the rumen epithelium, passing through the abomasum and/or neutralization with buffer (Bannink et al., 2012). In acute or sub-acute form (more common in dairy cows), there is a high concentration of lactic acid in the rumen, especially in animals in feedlot receiving finisher diets with high concentrations of starch and other fermentable carbohydrates (Pan et al., 2016). Due to a high dry matter intake and VFA production in the rumen, the profile of rumen microbial population changes and thereafter absorption of acids in the blood stream leads to acidosis (Enemark, 2008). In general, the symptoms of acidosis are increased levels of lactic acid in rumen and blood, decreased $\mathrm{pH}$ of blood and in rumen, increased osmotic pressure in rumen, death of gram-negative bacteria and the proliferation of gram-positive bacteria in rumen, reduction of the number of protozoa, changes in ruminal epithelium, reduction of urine $\mathrm{pH}$, dehydration, and hemoconcentration (Nagaraja \& Lechtenberg, 2007).

\section{Ruminal Microorganisms}

After the consumption of a high grain diet, non-structural carbohydrates appear in the rumen (by the physiological process), which after fermentation by the amylolytic bacteria which in turn leads to the production of pyruvate and finally VFA that result in the drop in ruminal $\mathrm{pH}$. This drop implies that many gram-negative bacteria, being sensitive to low due to their $\mathrm{pH}$ sensitivity, disappear, including lactate-consuming bacteria, like Megasphaera elsdenii and Selenomonas ruminantium (which convert lactate to pyruvate). The lactic acid bacteria growing under conditions of low rumen $\mathrm{pH}$ utilize lactic acid as an energy substrate, in addition to other substrates (Marx et al., 2011). Conversely, there is an increase in the population of some gram-positive bacteria, especially Streptococcus bovis, also known as lactate-producing bacteria. This change in the ruminal bacterial population further reduces ruminal $\mathrm{pH}$ by that is the increase in L-lactic acid, which is a very potent acid (10 times stronger than VFA). This to a leads to allowing the growth of only the $\mathrm{pH}$ resistant bacteria, such as, Lactobacillus spp., which are an (efficient lactate producer, especially of D-lactate). Thus, that leads ton additional in ruminal $\mathrm{pH}$ eventually drops to 3.8, which is the isoelectric point of this acid. At this $\mathrm{pH}$, at which the acid remains un-dissociated that results in the movement of the acid via the ruminal wall into the bloodstream leading to metabolic acidosis (Hernández et al., 2014).

Protozoa may represent $50 \%$ of the total microbial mass in the rumen. The significance of protozoa in the rumen is its their ability to engulf starch granules, which prevents rapid digestion and excessive acid production in the rumen (Van Soest, 1994). Therefore, protozoa possess the ability to modulate digestion of starch and reduce the chances of rumen acidosis. However, the slow replication time (5 to 24 hours) and the preference of $\mathrm{pH}$ above 5.8 for maximum growth lead to a decrease in the population of protozoa in rumen during acidosis (Valente et al., 2016). Extended periods of low rumen $\mathrm{pH}$ are probably more detrimental to the survival of ciliate protozoa in the rumen than the other factors (Franzolin \& Dehority, 2010).

\section{VFA Production in Rumen}

The animals with a high consumption of dry matter tend to intake more fermentable organic matter in the rumen, which results in the high production of volatile fatty acids, thereby increasing the risk of acidosis in lactating dairy cows and animals in a feedlot. The cattle fed exclusively on forage do not demonstrate digestive disorders, such as, acidosis. On the other hand, the supply of feed concentrates in the form of grains in the diet (to enhance the animal performance and energy consumption) increases the amount of carbohydrates to be fermented by rumen microorganisms that consequently promotes VFA production (Pourazard et al., 2016). The grains, which are rich in starch and sugars, increase ruminal fermentation. In addition to changing the diet composition, DMI also influences acid production in the rumen. The cattle with the highest feed intake produce the increased amount of VFA by ruminal fermentation and consequently are more susceptible to acidosis (Enemark, 2008).

When cellulolytic microorganisms digest cellulose, acetate production increases. The ratio of the main VFA, acetate, propionate and butyrate, is approximately 75:15:10. In the case, when starch and sugars are pre-dominant in the diet, the amylolytic microorganisms digest these carbohydrates and produce acetate, propionate, and butyrate in different proportions, in which the propionate keeps increasing, and the acetate and butyrate attain low 
molar concentrations (65:30:5). The microorganisms that digest starch and sugars proliferate faster than the cellulolytic and hemicellulolytic bacteria, as the rate of digestion of these carbohydrates is faster than the fermentation of cellulose and hemicelluloses (Valente et al., 2015; Pan et al., 2016). The ruminal pH is lower during digestion of starch as compared to cellulose. Such a change in the $\mathrm{pH}$ affects ruminal microbial growth as the cellulolytic microorganisms prefer $\mathrm{pH}$ above 6.5 , while the amylolytic microbes prefer a $\mathrm{pH}$ between 5.5 and 6.5 (Dijkstra et al., 2012). The ruminal acidosis cycle caused by excessive consumption of fermentable carbohydrates in the rumen is depicted in the Figure 1.

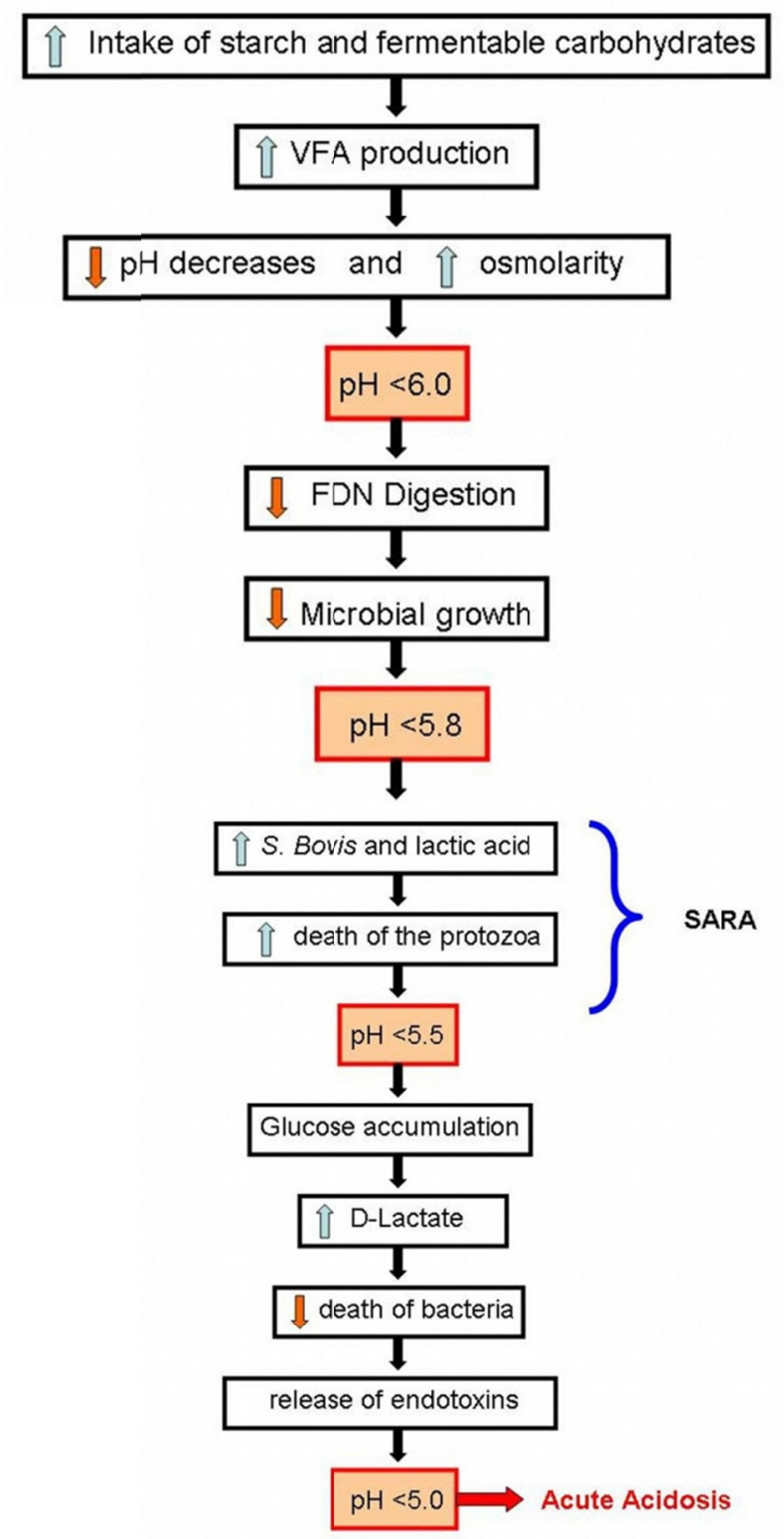

Figure 1. Ruminal acidosis cycle caused by excessive consumption of fermentable carbohydrates in the rumen

\section{Lactate Yield in Rumen}

Lactic acid, when produced, is immediately absorbed and converted into glucose in the liver or oxidized to provide energy to tissue. However, the lactic acid uptake is slower than that of the volatile fatty acids, such as acetic, propionic and butyric acids. In addition to its use for the synthesis of glucose, lactate is also important for the synthesis of acetate, which is required for lipogenesis in mammary glands. However, when animals suffer from acute acidosis, there is an increase in the stereoisomer of lactic acid, D-lactate, representing 10 to $20 \%$ of the total lactic acid concentration in rumen at an appropriate $\mathrm{pH}(\mathrm{pH}$ higher than 5.8). With a decline in the ruminal $\mathrm{pH}$, 
L-lactate concentration drops decreases, while that and the of D-lactate shows exaggerated increases excessively (representing $40 \%$ to $50 \%$ of lactic acid) in the rumen fluid. When absorbed, D-lactate is eliminated by oxidation (45\%), gluconeogenesis (14\%), and renal excretion (13\%). However, during acute acidosis, while D-lactate absorption increases, a greater fraction of the acid is excreted in urine (Van Soest, 1994; González et al., 2012). The differences between D-lactate and L-lactate molecules are shown in Figure 2.

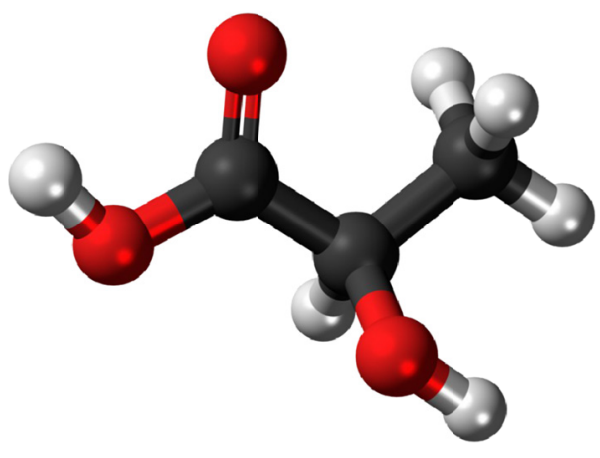

D-Lactic acid molecule

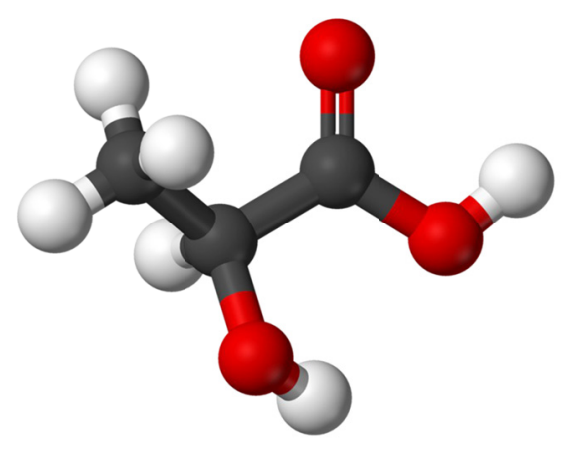

L-Lactic acid molecule

Figure 2. D-Lactic acid molecule and L-Lactic acid molecule (black ball = carbon; red ball = oxygen, white ball $=$ hydrogen)

\section{Ruminal pH}

The $\mathrm{pH}$ can vary according to the diet. However, it typically remains between 5.5 and 7.0, when the ruminants are predominantly on a forage diet. Acidosis in animals can influence blood $\mathrm{pH}$ since there is an increase in the absorption rate of rumen acids (Aschenbach et al., 2014). The plasma $\mathrm{pH}$ is maintained at a constant value with little variation, from 7.35 to 7.45 , which represents an $\mathrm{H}^{+}$concentration of $36-42 \mathrm{nmol} / \mathrm{L}$. The dissociation constant (pKa) of a substance is the $\mathrm{pH}$ at which the protonated and non-protonated forms are in equilibrium or in other words $50 \%$ fraction is in its dissociated form. A weak acid or a weak base is more effective as a buffer when the $\mathrm{pH}$ approaches its pKa. The pKa of propionic acid is 4.9 , that of acetic acid and butyric acid have pKa is 4.8 , and that forof lactic acid is 3.9. The $\mathrm{pKa}$ of these acids is low; therefore, the $\mathrm{pH}$ of organic acids that can have buffer action in the rumen is very low and incompatible with the physiological conditions of animals, especially in the case of lactic acid. The lactic acid dissociation constant is about 10 times higher than that of the main VFA. It is considered one of the strongest acids and thus has a greater influence on ruminal $\mathrm{pH}$ (Russell, 2002).

The VFA isare not completely absorbed in the rumen. Some of these acids are taken to the omasum and abomasum by the movement of the solid and liquid phase of the rumen after ruminal contractions. However, the continuous absorption of VFA by rumen epithelium is essential for maintaining osmotic balance and the appropriate $\mathrm{pH}$ of the rumen. VFA are absorbed by passive diffusion in the digestive tract and the rate of absorption of VFA is influenced by ruminal $\mathrm{pH}$. This primarily affects the acid dissociation rate (Krause \& Oetzel, 2006). When rumen $\mathrm{pH}$ is alkaline, small amounts of fatty acids are present in undissociated forms. As the $\mathrm{pH}$ of the liquid drops, the dissociation rate of fatty acids decreases, which promotes absorption through rumen epithelium, since only the undissociated form has the capacity to cross the basal membrane of the ruminal epithelium (Krause et al., 2014). Therefore, lower the ruminal $\mathrm{pH}$, greater is the rate of VFA absorption, which may affect blood $\mathrm{pH}$, especially when the lactic acid is present in the rumen. In addition to VFA accumulation in rumen during the rumen acidosis, glucose accumulates in the rumen fluid during acute acidosis. The digestion of starch by amylase results in the bacterial production of glucose, which is rapidly converted to pyruvate during glycolysis (Van Soest, 1994; Russell, 2002; Pan et al., 2016). Yet, in the period of acute acidosis, the glucose accumulation, is observed in ruminal fluid, does not go beyond $160 \mathrm{mg} / \mathrm{dL}$, which is still 2.5 to 3.0 times of blood plasma. The exact reason of glucose accumulation in the rumen is still unknown; despite, it seems that glycolysis may be partially blocked. The lactic acid concentration is high in dairy cows or animal feedlot, where rumen $\mathrm{pH}$ between 5.0 and 5.8 corresponds to $<2.0 \mathrm{mM}$ (Horn et al., 1979). However, the intake of NDF can have a positive effect on the ruminal $\mathrm{pH}$, and can effectively increase ruminal $\mathrm{pH}$. The presence of glucose in the rumen fluid may favor the proliferation of Streptococcus bovis accumulation, which, according to Hungate (1968), is the main responsible microorganism for lactic acidosis. Besides this, Lactobacillus spp. also promotes thes conversion of glucose/pyruvate into lactic acid 
affecting the $\mathrm{pH}$ of rumen. Meanwhile, the concentrations of these organisms in the cattle diets that are high in the concentrate are very low (Russell, 2002). Furthermore, the presence of glucose in the ruminal fluid reduces the adhesion of microorganisms to feed particles, especially the fibers, which extends the initial phase of NDF digestion, affecting the ruminal fiber digestion (Valente et al., 2016).

\section{Modern pH Measurement}

The modern wireless radio transmission mediated $\mathrm{pH}$ measurement system was used employed to continuously monitor the ruminal bottom $\mathrm{pH}$ in the cows. No significant difference was observed in the $\mathrm{pH}$ measurement by modern $\mathrm{pH}$ measurement system and the $\mathrm{pH}$ values determined by the spot-sample method (Sato et al., 2012). Penner et al. (2006) developed a $\mathrm{pH}$ tracing device for a lactating dairy cow that experienced SARA. The duration at which $\mathrm{pH}$ remained below the threshold value of 5.8 in a $24-\mathrm{h}$ period was used to characterize SARA. The events of sub-acute ruminal acidosis were noted as 6.4, 6.5, and $11.8 \mathrm{~h} / \mathrm{d}$ on Aug 5/6, 6/7, and 7/8, respectively. Although, indwelling ruminal $\mathrm{pH}$ monitoring systems are widely used in research, there is no reliable system for continuous measurement of ruminal $\mathrm{pH}$ in commercial dairy cows. The limitation to developing such a system is the need of the regular standardization of $\mathrm{pH}$ electrodes to avoid faulty errors results. More over. In addition, this technique will require cannulation of the rumen in cattle (Sato et al., 2012).

\section{Saliva and Buffering}

Saliva maintains normal rumen $\mathrm{pH}$ by neutralizing acids in the rumen, which influences the liquid passage rate by the removal of large amounts of acids. In fact, some researchers believe that one of the main functions of saliva is to increase the rate of passage of the liquid phase of the rumen and not necessarily to neutralize the acids produced by ruminal fermentation. When ruminants are fed on the diets that are rich in fiber, the rate of rumination and saliva production is increased (Hernández et al., 2014; Pan et al., 2016). This increases the rate of passage of the liquid phase by up to $20 \%$ per hour. This means that the large amounts of VFA are transferred from the rumen to the omasum and abomasum without being accumulated in the rumen, thereby providing insufficient time to VFA to cause changes in the rumen (Krause et al., 2014). The addition of bicarbonate and phosphate salts leads to recycling of urea in the rumen, which is readily hydrolyzed and converted into ammonia, which contributes to the buffering effect of the saliva in the rumen. If the consumption of fermentable organic matter (OM) increases in the rumen, it reduces the chewing rate and rumination of the ingested fermentable OM (Enemark, 2008; Aschenbach et al., 2014). This results in the elevated VFA production in the absence of a compensatory increase in the saliva buffering. Therefore, in such cases, an increase in the VFA absorption rate by ruminal epithelium and the increase in the rate of passage of the liquid and solid phases of the rumen mechanisms are critical to evaluate a possible accumulation of acids in the rumen (Hernández et al., 2014).

\section{Prevention of Ruminal Acidosis}

Ruminant animals are adapted to digest and metabolize predominantly forage diets. Thus, the growth rates and milk production are substantially increased when ruminants consume high-grain diets. One of the consequences of feeding excessive amounts of rapidly fermentable carbohydrates together with inadequate fiber to ruminants is the sub-acute ruminal acidosis, which is characterized by an episode of low ruminal $\mathrm{pH}$ that resolves without treatment and is rarely diagnosed (Krause et al., 2014). Dairy cows and feedlot cattle are at risk of developing such a condition. Acidosis can be prevented by formulating a diet that avoids excessive acid production in the rumen, and by adopting a suitable nutritional management that does not change microorganisms in the rumen (Liu et al., 2016) A gradual adaptation to the diet with higher amounts of grain is essential to avoid acute acidosis. Feedlots using termination diets with large amounts of starch should initially be adapted by giving two or even three diets with increasing concentrations of grain. The use of fatty by-products may be an alternative to decrease the use of starch-rich feeds without compromising the energy levels offered by provided by a diet (Lima et al., 2015, 2016). The cattle undergoing dietary restriction for several hours may have acidosis due to an increase in the initial intake. The frequency of feed supply is important in feedlots, especially in finishing diets. In certain cases, the use of diets that restrict consumption by $90 \%$ to $95 \%$ may improve feed efficiency and minimize the chances of excessive DMI and the risk of acidosis. A gradual adaptation to the diets those are rich in starch reduces the variation in the ruminal $\mathrm{pH}$ during the day, which results in the maintenance of a high $\mathrm{pH}$ and the reduction of the risk of acidosis (Dijkstra et al., 2012).

The use of additives, such as ionophores, monensin, and lasalocid, in the feed is a common practice not only to reduce the incidence of rumen acidosis but also to improve feed conversion efficiency due to an increase in the energy content of the ruminant diet. Ionophores, in the rumen, form soluble complexes with cations, facilitating movement of these ions across the cell membrane of rumen bacteria (Russell \& Strobel, 1989; Lana \& Russell, 1996). Other feed additives, such as, buffering agents (sodium bicarbonate) are constantly used in feedlot diets. 
The addition of $0.5 \%$ to $1.0 \%$ of sodium bicarbonate in the dry diet reduces ruminal $\mathrm{pH}$ fluctuations, offers a buffering effect, and increases in sodium ion concentration in the rumen, which affects the passing rate of the liquid phase. The supply of NDF in the diet demonstrated various effects in reducing ruminal acidosis. First, an increase in the amount of NDF in the diet led to the reduction of starch, thereby leading to the dilution of fermentable carbohydrates in the rumen (Bampidis \& Robinson, 2006). The ruminal fermentation by the cellulolytic microorganisms does not result in the production of lactic acid, and the incidence of lactic acidosis tends to be minimized when NDF or pectin is added to the diet (Ariza et al., 2001; Arthington et al., 2002). The fact that the addition of NDF in diet dilutes the ruminal fermentation of other carbohydrates implies that seems imperative that NDF must possess a physical structure that is able to stimulate rumination and salivation. The particle size and density or the supply of forage NDF affects the effective capacity of a feed to stimulate rumen motility (Valente et al., 2011). The particle size of NDF is the most important feature for the stimulation of fermentation, as at least $1.2 \mathrm{~mm}$ sized particles are necessary to render NDF physically effective for the stimulation of rumination (Mertens, 1997; Liu et al., 2016).

The use of living or dead yeast cultures, such as certain strains of Saccharomyces cerevisiae, favors ruminal fiber digestion, which increases the population of microorganisms that utilize lactic acid and reduce the $\mathrm{pH}$ fluctuation of ruminal fluid (Gonzalez et al., 2014).

\section{Treatment of Acidosis}

The treatment of acute acidosis is based on the removal of the cause of the problem (the removal of the source of starch) and the restoration of acid-base balance in the animal. The main measures need to be taken are for the intake of a proper diet and taking care of dehydration and acidosis. The use of alkali laxatives (magnesium carbonate or bicarbonate, $200-450 \mathrm{~g} / \mathrm{animal}$ ) is satisfactory only in mild cases. In certain cases emptying the rumen by using a tube (cannula) is required. The use of oils and fermentation controller may be useful to assist evacuation and reduce absorption of acids and toxins. An oral administered of antibiotics, such as penicillin (5-10 million IU/adult animal) or tetracycline (8-10 g/adult animal), orally can control the growth of lactic acid producing bacteria (Michell, 1990). It is important to restrict the consumption of water in the diseased animals, as an excessive consumption of water can cause the undesirable distribution of body fluids, with worsening the electrolyte imbalance. Anti-histamines can be used to prevent intoxication and laminitis, although its use is now controversial. The use of thiamine hydrochloride is indicated in some reports. During the recovery period, animals must receive water and good quality roughage with gradual re-introduction of grains to the cattle diet.

Pan et al. (2016) studied the effects of grain-induced SARA on thiamine status in blood and rumen fluid in dairy cows. A The diet composed of $33.2 \%$ starch, dry matter, and thiamine ( $180 \mathrm{mg}$ of thiamine $/ \mathrm{kg}$ of dry matter intake) was fed to the dairy cows. The ruminal $\mathrm{pH}$ and the concentrations of thiamine, acetate, and VFA in the rumen were reported to increase, whereas ruminal lactate contents were reduced by thiamine supplementation. The concentrations of lactate and the activity of lactate dehydrogenase in blood were reduced due to thiamine supplementation. Thus, it can be stated that thiamine status was affected by SARA in dairy cows and the ruminal infusion of thiamine could help attenuate SARA by the improvement of in the proportions of ruminal VFA and the reduction of lactate contents in rumen fluid and blood (Russell, 2002).

\section{Conclusion}

The low ruminal $\mathrm{pH}$ is caused by the excessive accumulation of VFA without persistent lactic acid accumulation and is restored to normal by the physiological processes in animals.

To prevent SARA acidosis, a ruminal adaption to high-grain diets is required along with limited intake of readily fermentable carbohydrates. This requires both, a good diet formulation wherein fiber and non-fiber carbohydrates are appropriately balanced and a good feed bunk management.

An adequate supply of NDF in the animal diet with larger particle size and length is recommended so as to stimulate rumination and subsequent enhancement of buffering, thus maintaining the balance between $\mathrm{pH}$ and microorganisms in the rumen.

\section{References}

Archimède, H., Sauvant, D., \& Schmidely, P. (1997). Quantitative review of ruminal and total tract digestion of mixed diet organic matter and carbohydrates. Reprod. Nutr. Dev., 37, 173-189. https://doi.org/10.1051/ rnd:19970205

Ariza, P., Bach, A., Stern, M. D., \& Hall, M. B. (2001). Effects of carbohydrates from citrus pulp and hominy feed on microbial fermentation in continuous culture. J. Anim. Sci., 79, 2713-2718. https://doi.org/10.2527/ 2001.79102713x 
Arthington, J. D., Kunkle, W. E., \& Martin, A. M. (2002). Citrus pulp for cattle. Vet. Clin. Food Anim., 18, 317-326. https://doi.org/10.1016/S0749-0720(02)00023-3

Aschenbach, J. R., Penner, G. B., Stumpff, F., \& Gabel, G. (2014). Ruminant nutrition symposium: Role of fermentation acid absorption in the regulation of ruminal pH. J. Anim. Sci., 89, 1092-1107. https://doi.org/10.2527/jas.2010-3301

Bampidis, V. A., \& Robinson, P. H. (2006). Citrus by-products as ruminant feeds: A review. Animal Feed Science and Technology, 128(3), 175-217. https://doi.org/10.1016/j.anifeedsci.2005.12.002

Bannink, A., Gerrits, W. J. J., France, J., \& Dijkstra, J. (2012). Variation in rumen fermentation and the rumen wall during the transition period in dairy cows. Animal Feed Science and Technology, 172, 80-94. https://doi.org/10.1016/j.anifeedsci.2011.12.010

Dijkstra, J., Ellis, J. L., Kebreab, E., Strathe, A. B., López, S., France, J., \& Bannink, A. (2012). Ruminal pH regulation and nutritional consequences of low pH. Anim. Feed Sci. Technol., 172, 22-33. https://doi.org/10.1016/j.anifeedsci.2011.12.005

Enemark, J. M. D. (2008). The monitoring, prevention and treatment of sub-acute ruminal acidosis (SARA): A review. Vet. J., 176, 32-43. https://doi.org/10.1016/j.tvj1.2007.12.021

Franzolin, R., \& Burk, A. D. (2010). The role of pH on the survival of rumen protozoa in steers. Bras. J. Anim. Sci., 39, 2262-2267. https://doi.org/10.1590/s1516-35982010001000023

Gonzalez, A. R. C., Barraza, M. E. B., Viveros, J. D., et al. (2014). Microorganismos y fermentación ruminal. Arch. Med. Vet., 46, 349-361. https://doi.org/10.4067/S0301-732X2014000300003

González, L. A., Manteca, X., Calsamiglia, S., Schwartzkopf-Genswein, K. S., \& Ferret, A. (2012). Ruminal acidosis in feedlot cattle: Interplay between feed ingredients, rumen function and feeding behavior (a review). Animal Feed Science and Technology, 172, 66-79. https://doi.org/10.1016/j.anifeedsci.2011.12.009

Hernández, J., Benedito, J. L., Abuelo, A., \& Castillo, C. (2014). Review Article. Ruminal acidosis in feedlot: From aetiology to prevention. The Scientific World Journal, Article ID 702572. http://dx.doi.org/10.1155/ 2014/702572

Horn, G. W., Gordon, J. L., Prigge, E. C., \& Owens, F. N. (1979). Dietary buffers and ruminal and blood parameters of subclinical lactic acidosis in steers. J. Anim. Sci., 48, 683-691. https://doi.org/10.2527/ jas1979.483683x

Hungate, R. E. (1968). Ruminal fermentation. In C. F. Code (Ed.), Handbook of Physiology (Chap. 130, Sec. 6, pp. 2725-2745). American Physiology Society, Washington, DC.

Krause, D. O., Nagaraja, T. G., Wright, A. D., \& Callaway, T. R. (2014). Board-invited review: Rumen microbiology: Leading the way in microbial ecology. J. Anim. Sci., 91, 331-334. https://doi.org/10.2527/jas. 2012-5567

Krause, K. M., \& Oetzel, G. R. (2006). Understanding and preventing subacute ruminal acidosis in dairy herds: A review. Animal Feed Science and Technology, 126, 215-236. https://doi.org/10.1016/j.anifeedsci. 2005.08.004

Lana, R. P., \& Russell, J. B. (1996). Use of potassium depletion to assess adaptation of ruminal bacteria to ionophores. Appl. Environ. Microbiol., 62, 4499-4503.

Lima, E. S., Morais, J. P. G., Roça, R. O., Andrade, E. N., Valente, T. N. P., Costa, Q. P. B., \& Deminicis, B. B. (2015). Effect of different sources of lipids in diet on the qualitative characteristics of Longissimus thoracis muscle of cattle finished in feedlots. African Journal Agricultural Research, 10, 2835-2840. http://dx.doi.org/10.5897/AJAR2015.10064

Lima, E. S., Morais, J. P. G., Roça, R. O., Valente, T. N. P., Andrade, E. N., \& Deminicis, B. B. (2016). Performance and carcass characteristics of cattle fed lipid sources in the diet. Can. J. Anim. Sci., 96, 581-588. http://dx.doi.org/10.1139/cjas-2015-0203

Liu, Y. F., Sun, F. F., Wan, F. C., Zhao, H. B., Liu, X. M., You, W., ... Song, E. L. (2016). Effects of three feeding systems on production performance, rumen fermentation and rumen digesta particle structure of beef cattle. Asian Australas. J. Anim. Sci., 29, 659-665. http://dx.doi.org/10.5713/ajas.15.0445 
Marx, H., Graf, A. B., Tatto, N. E., Thallinger, G. G., Mattanovich, D., \& Sauer, M. (2011). Genome sequence of the ruminal bacterium Megasphaera elsdenii. J. Bacteriol., 193, 5578-5579. https://doi.org/10.1128/ JB.05861-11

Mertens, D. R. (1997). Creating a system for meeting the fiber requirements of dairy cows. J. Dairy Sci., 80, 1463-1481. https://doi.org/10.3168/jds.S0022-0302(97)76075-2

Michell, B. (1990). Ruminant acidosis. In Practice, 12(6), 245-249. https://doi.org/10.1136/inpract.12.6.245

Nagaraja, T. G., \& Lechtenberg, K. F. (2007). Acidosis in feedlot cattle. Veterinary Clinics of North America -Food Animal Practice, 23, 333-350. https://doi.org/10.1016/j.cvfa.2007.04.002

Owens, F. N., \& Basalan, M. (2016). Ruminal Fermentation. Ruminology (pp. 63-102). Springer. https://doi.org/10.1007/978-3-319-30533-2_3

Pan, X. H., Yang, L., Xue, F. G., Xin, H. R., Jiang, L. S., Xiong, B. H., \& Beckers, Y. (2016). Relationship between thiamine and subacute ruminal acidosis induced by a high-grain diet in dairy cows. Journal of Dairy Science, 99, 8790-8801. https://doi.org/10.3168/jds.2016-10865

Penner, G. B., Beauchemin, K. A., \& Mutsvangwa, T. (2006). An evaluation of the accuracy and precision of a stand-alone submersible continuous ruminal pH measurement system. J. Dairy Sci., 89, 2132-2140. https://doi.org/10.3168/jds.S0022-0302(06)72284-6

Plaizier, J. C., Krause, D. O., Gozho, G. N., \& McBride, B. W. (2009). Subacute ruminal acidosis in dairy cows: The physiological causes, incidence and consequences. The Veterinary Journal, 176, 21-31. https://doi.org/10.1016/j.tvj1.2007.12.016

Pourazad, P., Khiaosa-Ard, R., Qumar, M., Wetzels, S. U., Klevenhusen, F., Metzler-Zebeli, B. U., \& Zebeli, Q. (2016). Transient feeding of a concentrate-rich diet increases the severity of subacute ruminal acidosis in dairy cattle. J. Anim. Sci., 94, 726-738. https://doi.org/10.2527/jas.2015-9605

Russell, J. B. (2002). Rumen Microbiology and its role in ruminant nutrition (p. 119). Ithaca, NY.

Russell, J. B., \& Strobel, H. J. (1989). The effect of ionophores on rumen fermentation. Appl. Environ. Microbiol., 55, 1-6.

Sato, S., Kimura, A., Anan, T., et al. (2012). A radio transmission pH measurement system for continuous evaluation of fluid $\mathrm{pH}$ in the rumen of cows. Vet Res Commun, 36, 85. http://dx.doi.org/10.1007/s11259012-9518-X

Valente, T. N. P., Detmann, E., \& Sampaio, C. B. (2015). Review: Recent advances in evaluation of bags made from different textiles used in situ ruminal degradation. Can. J. Anim. Sci., 95, 493-498. https://doi.org/ 10.4141/cjas-2015-100

Valente, T. N. P., Detmann, E., Queiroz, A. C., Valadares Filho, S. C., Gomes, D. I., \& Figueiras, J. F. (2011). Evaluation of ruminal degradation profiles of forages using bags made from different textiles. Braz. J. Anim. Sci., 40, 2565-2573. https://doi.org/10.1590/s1516-35982011001100039

Valente, T. N. P., Lima, E. S., Santos, W. B. R., Cesario, A. S., Tavares, C. J., Fernandes, I. L., \& Freitas, M. A. M. (2016). Ruminal microorganism consideration and protein used in the metabolism of the ruminants: A Review. Afr. J. Microbiol. Res., 10, 456-464. https://doi.org/10.5897/AJMR2016.7627

Van Soest, P. J. (1994). Nutritional Ecology of the Ruminant (p. 476). Cornell University Press.

Van Vuuren, A. M., Calsamiglia, S., \& Úden, P. (2012). Rumen Health: A $360^{\circ}$ Analysis. Anim. Feed Sci. Technol., 172, 1-3. https://doi.org/10.1016/j.anifeedsci.2011.12.002

\section{Abbreviations}

DM, dry matter; DMI, dry matter intake; NDF, neutral detergent fiber; OM, organic matter; SARA, sub-acute ruminal acidosis; VFA, volatile fatty acids.

\section{Copyrights}

Copyright for this article is retained by the author(s), with first publication rights granted to the journal.

This is an open-access article distributed under the terms and conditions of the Creative Commons Attribution license (http://creativecommons.org/licenses/by/4.0/). 